\title{
ATUAÇÃO DO ENFERMEIRO NA PROMOÇÃO DA IMUNIZAÇÃO CONTRA O PAPILOMAVÍRUS HUMANO (HPV) E SUA CORRELAÇÃO COM A PREVENÇÃO DO CÂNCER DO COLO DE ÚTERO
}

\author{
Stéfani Coutinho Lobo ${ }^{1}$ \\ Fabíola Vargas Apolinário²
}

RESUMO: A infecção pelo Papilomavírus Humano (HPV) é considerada a infecção sexualmente transmissível de maior incidência mundial e estima-se que haja cerca de 600 milhões de pessoas infectadas pelo HPV no mundo e que $80 \%$ da população sexualmente ativa já tenha entrado em contato com o vírus em algum momento da vida. É importante discorrer desse tema tendo em vista que a alta infecção de jovens pelo HPV é um grave problema que possui prevalência significativa, além do mais, esta infecção apresenta-se de forma assintomática com lesões inaparentes que somente são visíveis se houver a aplicação de reagentes (KRABBE et al, 20I6), dificultando o seu diagnóstico inicial. O objetivo geral do presente trabalho é analisar o papel do enfermeiro diante dos fatores relacionados ao câncer de colo de útero e os sintomas, diagnóstico, tratamento e prevenção dessa patologia e a imunização contra o Papilomavírus Humano. Trata-se de um estudo acerca do Câncer de Colo de Útero e o papel do enfermeiro quanto a prevenção do câncer dada a importância da realização de exames periódicos de rotina da colpocitologia oncótica, mais conhecida como Exame Papanicolau ou Exame Preventivo e a vacinação contra o HPV. Dessa forma, a pesquisa pode ser classificada como uma revisão bibliográfica cujos procedimentos metodológicos incluíram pesquisa bibliográfica de abordagem qualitativa. Conclui-se que o tema da presente pesquisa tem bastante relevância quanto a promoção da saúde da mulher, além de que se pode perceber o papel fundamental que o enfermeiro tem diante do enfrentamento do câncer de do colo do útero, desde da prevenção com a promoção da vacina ao tratamento do mesmo.

Palavras-chave: Câncer do colo do útero enfermeiro. Vacinação. Papilomavírus Huma

ABSTRACT: Human Papillomavirus (HPV) infection is considered the sexually transmitted infection with the highest incidence in the world and it is estimated that there are approximately 600 million people infected with HPV in the world and that $80 \%$ of the sexually active population has already come into contact with it. virus at some point in life. It is important to discuss this topic considering that the high infection of young people by $\mathrm{HPV}$ is a serious problem that has a significant prevalence. Furthermore, this infection presents itself asymptomatically with non-apparent lesions that are only visible if reagents are applied. (KRABBE et al, 2016), making its initial diagnosis difficult. The general objective of this study is to analyze the role of nurses in the face of factors related to cervical

\footnotetext{
${ }^{I}$ Graduanda em Enfermagem pela UniREDENTOR, Itaperuna - RJ. E-mail: stefanityf2@gmail.com

${ }^{2}$ Docente de Enfermagem pela UniREDENTOR, Itaperuna - RJ. E-mail:

fabiola.apolinario@uniredentor.edu.br
} 
cancer and the symptoms, diagnosis, treatment and prevention of this pathology and immunization against the Human Papillomavirus. This is a study about Cervical Cancer and the role of nurses in cancer prevention given the importance of carrying out periodic routine examinations of oncotic colpocytology, better known as Pap smear or Preventive Examination and vaccination against the HPV. Thus, the research can be classified as a literature review whose methodological procedures included a qualitative literature review. It is concluded that the theme of this research is very relevant in terms of promoting women's health, in addition to the fundamental role that nurses play in coping with cervical cancer, from prevention to promotion. from vaccine to treatment.

Keywords: Cervical cancer. nurse. vaccination. Human Papiloma Vírus. I

\section{INTRODUÇÃO}

A infecção pelo Papilomavírus Humano (HPV) é considerada a infecção sexualmente transmissível de maior incidência no mundo e estima-se que haja cerca de 600 milhões de pessoas infectadas pelo HPV e que 80\% da população sexualmente ativa já tenha entrado em contato com o vírus em algum momento da vida (CARDIAL et al., 2019).

O Programa Nacional de Imunização é referência no mundo por sua cesta de imunobiológicos e, em 2014 introduziu a vacina contra o HPV (Papilomavírus Humano) no calendário Nacional de vacinação ( $\mathrm{MORO}$ et al, 2017). A introdução da vacina justifica-se pelas estimativas mundiais que apontam aproximadamente $530 \mathrm{mil}$ casos novos e $275 \mathrm{mil}$ mortes por câncer do colo do útero ao ano, sendo $88 \%$ desses óbitos em países em desenvolvimento. No Brasil e no mundo se constitui como a segunda causa de morte por câncer entre mulheres (BRASIL, 2021).

Existem vários fatores associados ao aparecimento do câncer, porém, a principal causa do Câncer do Colo do Útero, são os tipos oncogênicos: HPV 6, II, I6 e I8. Quando presente somente o agente, este não é um fator determinante para a manifestação dos casos, porém quando associados aos fatores comportamentais e culturais, o HPV está relacionado para a formação das lesões do CCU (BARBOSA e NIQUILIRO, 2016).

De acordo com Moro et al (2017), estratégia adotada pelo Ministério da Saúde para prevenir o HPV foi vacinar meninas de 9 a 13 anos, II meses e 29 dias. No primeiro ano de vacinação, 20I4, o alvo da campanha foram as meninas de II anos à 13 anos II meses e 29 dias. Foi primeiramente realizada nas escolas e a segunda dose foi oferecida nas Unidades de Saúde do SUS ou nas escolas, conforme preferência dos municípios. O esquema vacinal indicado para o HPV é de duas doses da vacina, a primeira no dia o e segunda seis meses após a primeira. Já para os meninos, a vacina é ofertada no calendário de imunização a partir 
dos II anos, sendo o esquema vacinal organizado da mesma forma: a primeira dose no dia o e a segunda administrada 6 meses após a primeira. (BRASIL, 202I).

Dessa forma, a imunização é entendida como um transformador no curso das doenças, em virtude do acentuado decréscimo da morbidade e da mortalidade que são causadas pelas doenças infecciosas evitáveis por vacinas. Configura-se como o melhor procedimento e efetividade com promoção e proteção da saúde dos indivíduos. E com as altas coberturas vacinais podem gerar impacto no comportamento epidemiológico das doenças imunopreviníveis (NORA et al, 2016).

A vacinação contra o Papilomavírus Humano é de extrema importância para prevenção do câncer do colo do útero, os dados epidemiológicos revelam a necessidade de ações para prevenção do câncer de colo uterino. A vacina contra os vírus mais oncogênicos mostrou-se eficaz no combate à doença, com relevante custo benefício (HINO et al, 2016).

As considerações de enfermagem em oncologia evoluíram muito desde seu aparecimento como as especialidades, e a literatura existente aponta e preconiza importante papel da enfermagem no apoio ao cliente oncológico nas várias fases de sua doença (CAMARGO; SOUZA, 2003).

É importante discorrer desse tema tendo em vista que a alta infecção de jovens pelo HPV é um grave problema que possui a maior prevalência em todo o mundo. Além do mais, esta infecção apresenta-se de forma assintomática com lesões inaparentes que somente são visíveis se houver a aplicação de reagentes (KRABBE et al, 2016), dificultando o seu diagnóstico inicial.

O objetivo geral do presente trabalho é discorrer sobre a relação do Papiloma Virus Humano (HPV) e o Câncer do Colo do Útero e o papel do enfermeiro nas unidades básicas de saúde como articulador da vacinação contra o HPV como ferramenta promotora da saúde.

\section{MATERIAIS E MÉTODOS}

O ponto de partida da presente pesquisa será realizar uma pesquisa de revisão bibliográfica de abordagem qualitativa, buscando teoria em livros, artigos, dissertações, teses e plataformas digitais como Google Acadêmico e Scielo que citam os assuntos com o objetivo de apresentar o tema relatado da maneira mais clara possível, permitindo o enriquecimento de informações e o aprofundamento de nossa opinião sobre o tema tratado na presente pesquisa. Os critérios de exclusão foram materiais que não atenderam aos 
objetivos gerais ou que pertencessem a plataformas de informações não confiáveis.

\section{DISCUSSÃO}

O Papilomavírus Humano (HPV) é uma doença imunoprevenível que está relacionada ao Câncer do Colo de Útero (CCU), caracterizado como um problema de saúde pública, sendo considerado uma infecção sexualmente transmissível (IST) com grande prevalência em todo o mundo e com alta taxa de mortalidade em nosso país. Segundo as estimativas de incidências e mortalidade de CCU no ano de 2003, o carcinoma de colo de útero é um dos principais responsáveis pelas mortes do sexo feminino no Brasil (SANTOS et al, 2016).

O HPV penetra no epitélio através de microfissuras ou no colo uterino pelas células metaplásicas e atinge as células das camadas profundas, infectando-as. Esse vírus tende a escapar da resposta imune do hospedeiro e pode permanecer latente por tempo indeterminado, ou ascender às camadas superficiais do epitélio, utilizando a maturação e diferenciação das sucessivas camadas epiteliais. E pode se propagar para as células vizinhas. Ele assume duas formas de atuação na célula: a forma epissomal, que corresponde ao mecanismo utilizado para produzir cópias virais; ou a forma integrada ao DNA do hospedeiro e, neste caso, na presença de outros cofatores, pode ser iniciado o processo de oncogênese (CARDIAL et al., 2019, p. 2).

É válido lembrar que a administração da vacina contra o HPV não supre ações de promoção da saúde, sendo assim, os pacientes vacinados devem receber orientação quanto ao uso de preservativos para a prevenção de infecção por outros tipos de HPV não incluídos nas vacinas e de outras infecções sexualmente transmissíveis (CARDIAL et al., 2019).

A falta de informação, principalmente dos pais quanto ao risco causado pelo HPV, gera grandes prejuízos quanto a vacinação, já que a recusa para a aplicação da vacina em muitos casos se dá principalmente pelo fato de que, a vacina induz seus filhos a iniciarem a vida sexual (CARVALHO, 2019; PEREIRA E SOUZA, 2017).

Segundo Machado e Alcântara (2016) o HPV nos últimos anos, tem sido uma das IST mais comuns, mais que pode ser prevenida por vacina, porém não havendo a prevenção, são capazes de causar o câncer do colo uterino, como também as verrugas genitais.

Cardial et al., (2019) relata que é segura a vacina do HPV, além de ser altamente eficaz na prevenção contra o câncer de colo de útero e doenças associadas aos tipos de HPV contidos na vacina. Sendo assim, a cobertura vacinal entre homens e mulheres abrandará a prevalência do vírus na população no futuro, porém, apesar disso, a orientação atual é de conservar o rastreio periódico de câncer de colo de útero através da colpocitologia oncótica 
(Exame Preventivo) e a prevenção de outras infecções sexualmente transmissíveis. É imprescindível a cobertura vacinal ampla para que os efeitos populacionais sejam realidade no futuro.

A vacina quadrivalente disponibilizada nas Unidades Básicas de Saúde (UBS) e em demais centros de Imunização é administrada através de duas doses e com intervalo de seis meses de uma para outra. Os países que adotaram o esquema de vacinação nas escolas, obtiveram ótimos resultados de adesão, já aqueles países que incluíram a vacina em Unidades Básicas de Saúde (UBS) na segunda fase, tiveram dificuldade para atingir os indicadores (DENARDIM, 202I).

Os sinais e sintomas do HPV incluem o aparecimento de verrugas com aspecto couve-flor de tamanhos variáveis, nos órgãos genitais. Esses sintomas estão relacionados ao aparecimento de alguns tipos de câncer, principalmente no colo do uterino, mas também no pênis, ânus ou boca. Portanto nem todo caso de infecção pelo HPV irá causar câncer de colo de útero (SILVA et al, 2020).

A transmissão é feita por contato de pele e relação sexual com alguém que tenha a infecção, ressaltando que os tipos virais são sítios específicos. O período de incubação do condiloma acuminado é de 3 a 8 semanas (SILVA et al, 2016).

Picconi e Teyssié (2014) asseveram que o amplo impacto (HPV) no campo da saúde surgiu com o conhecimento de seu potencial oncogênico e sua associação com tumores humanos, especialmente o câncer do colo do útero.

O Câncer de Colo de Útero é considerado um grande problema de saúde pública, pelo fato das chances de morte e sua incidência aumentada com o passar dos anos, ficando entre as quatro neoplasias que mais matam em idade precoce, antes dos setenta anos de idade (DERNARDIM, 2021).

Certos tipos de HPV são admitidos como fator causal necessário, porém não suficiente, na etiopatogenia da lesão neoplásica. O desenvolvimento do câncer cervical é menos provável na ausência da infecção pelo HPV e de fatores coexistentes, que favorecem a persistência da infecção, entre os quais: tabagismo, uso de contraceptivos orais, antecedente de múltiplos parceiros sexuais, multiparidade (SILVA et al. 2006, p. 286).

A prevenção primária do câncer do colo do útero está relacionada à diminuição do risco de contágio. A transmissão da infecção ocorre por via sexual, presumidamente por meio de abrasões microscópicas na mucosa ou na pele da região anogenital. Consequentemente, o uso de preservativos (camisinha masculina ou feminina) durante a 
relação sexual com penetração protege parcialmente do contágio pelo HPV, que também pode ocorrer pelo contato com a pele da vulva, região perineal, perianal e bolsa escrotal (INCA, 202I).

Mulheres sexualmente ativas e mulheres que já tiveram infecção pelo HPV não têm contraindicação em receber a vacina. O tratamento das lesões HPV-induzidas associado à vacinação pode reduzir a recorrência da doença (CARDIAL et al., 2019).

A infecção pelo vírus geralmente é transitória, desaparecendo de maneira espontânea, sendo estimado que aproximadamente 80\% de todas as mulheres irão em algum momento da vida se contaminar com algum tipo de HPV (CABUYA et al., 2020; SEQUERA, MATAMOROS, MENDOZA-LEON, 2020).

Os fatores de risco para o desenvolvimento do câncer do colo de útero são: início precoce da atividade sexual, multiplicidade de parceiros, multiparidade, predisposição genética, estado imunológico, más condições de higiene e alimentação, tabagismo, uso de contraceptivos orais, coinfecção por Chlamydia trachomatis e vírus da imunodeficiência humana, entre outros (ZARDO et al, 2014; BRASIL, 2013).

Alguns fatores de risco também estão relacionados com a doença como: tabagismo, início precoce da vida sexual, vários parceiros sexuais, baixa higiene, imunidade baixa, uso de anticoncepcionais, múltiplas gestações, idade, situação econômica, entre outros (INCA, 2021).

O câncer do colo do útero é uma doença de desenvolvimento lento, que pode não apresentar sintomas em fase inicial. Nos casos mais avançados, pode evoluir para sangramento vaginal intermitente ou após a relação sexual, secreção vaginal anormal e dor abdominal associada a queixas urinárias ou intestinais (INCA, 2021).

Os autores afirmam que uma das admissíveis explicações para a dispersão do HPV e a sua alta relação com o desenvolvimento do câncer de colo de útero é que nos últimos anos, as população passou a apresentar um número maior de parceiros sexuais, iniciando assim, de forma mais precoce sua vida sexual, assim como fazem o uso de contraceptivos hormonais orais e do tabaco cada vez mais cedo, expondo-se mais frequentemente aos fatores de risco associados à persistência viral do HPV e à progressão da doença em direção ao desenvolvimento do câncer (COLATINO, 2010; RAMOS, 2013).

Carvalho, Costa e França (2019) asseveram que de acordo com a Organização Mundial de Saúde (OMS), o desenvolvimento do câncer cervical em mulheres que 
apresentam sistema imunológico normalmente se dá em cerca de 15 a 20 anos, assim como para mulheres que apresentam sistema imunológico debilitado, quanto no caso de mulheres infectadas pelo vírus HIV e que não tem acesso ao tratamento, o aumento dessa neoplasia pode ocorrer de forma mais rápida, geralmente leva entre 5 e io anos.

O tratamento para cada caso deve ser avaliado e orientado por um médico. Entre os tratamentos para o câncer do colo do útero estão a cirurgia, a quimioterapia e a radioterapia. O tipo de tratamento dependerá do estadiamento (estágio de evolução) da doença, tamanho do tumor e fatores pessoais, como idade da paciente e desejo de ter filhos (INCA, 202I).

Para reverter esse panorama de alta incidência de câncer de colo de útero nas
mulheres em todo o mundo é essencial que essas mulheres tenham acesso à
informação. É necessário que conheçam as formas de prevenção e detecção precoce
da doença e que utilizem desses procedimentos para evitar o contágio por HPV e
o consequente desenvolvimento de um possível câncer de colo de útero. As
estratégias preventivas e de diagnóstico precoce são fundamentais para diminuir a
incidência mundial da doença (CARVALHO, COSTA E FRANÇA, 2019, p. 27o).

A maior parte dos artigos utilizados indica que a principal ação do enfermeiro é levar a informação aos pais e adolescentes, realizando ações educativas contra o HPV, uma vez que a educação em saúde representa uma ferramenta adicional para propagação da importância do uso de preservativos em todas as relações sexuais, orientando e conscientizando que o HPV é uma grave doença com consequências que pode levar ao câncer, porém há prevenção, e sua principal forma de prevenir é a vacinação em massa (MEIRELES et al., 2020).

O papel dos enfermeiros tem sido bastante amplo, mas por sua proximidade com a população, uma educação em saúde de maneira integral, estimulando as consultas de enfermagem, abordagens para esclarecimento de dúvidas, riscos, sinais e sintomas, pois essas práticas favorecem mudanças de comportamentos e de atitudes das mulheres (MISTURA et al., 2011; AMARAL et al., 2017).

Segundo Jorge e Silva (2010) o enfermeiro contribui para a melhora é o bem-estar das mulheres portadoras do CCU. Tem como proposta feita pela Organização Mundial da Saúde (OMS), o enfermeiro sempre estar avaliando a qualidade de vida como fatores físicos, psicológicos e relações sociais.

Quanto a educação em saúde é necessária que o enfermeiro aborde a relevância da realização do Papanicolau periodicamente e os riscos ao deixar de realizá-lo, sempre explicando como o exame é feito, assim promovendo vínculo enfermeiro-cliente minimizando preconceitos e mitos sobre o exame, promovendo um ambiente adequado, 
passando confiança para que as mulheres possam falar suas lamentações e dúvidas (NASCIMENTO, 2010; BATISTA, 2015)

O enfermeiro possui uma alta responsabilidade nas ações relacionadas a vacinação. Entretanto na maior parte das vezes o enfermeiro limita-se apenas a executar a técnica. Por isso é essencial que o enfermeiro realize ações educativas para melhorar a taxa de vacinação, esclareça notícias falsas, dúvidas frequentes, exponha informações sobre a vacina e possíveis eventos adversos e construa uma relação com a população na qual é responsável (MEIRELES et al, 2020).

Segundo Vasconcelos et al (20II) o papel exercido pelo enfermeiro na prevenção e controle do CCU é fundamental, já que ele atua em diversas áreas de estratégias educativas em saúde da mulher.

De acordo com Costa et al., (2017), o enfermeiro por conhecer a comunidade, pode direcionar atividades de acordo com o perfil, para tal, pode contar com apoio de Agentes Comunitários de Saúde, e para uma atuação ativa de educação em saúde deve-se instruir profissionais de enfermagem a recomendar mulheres em salas de espera a marcar consultas com a enfermeira ou médico para realização do Papanicolau.

O enfermeiro possui um papel fundamental no contexto da prevenção do CCU que é elaborar atividades como esclarecimento de dúvidas, prevenção de fatores de risco, realização de consultas ginecológicas e coleta do exame citopatológico, influenciando para um atendimento de melhor qualidade que atenda à demanda, e intervindo para o encaminhamento adequado (RAMOS et al, 2014), concentrando esforços para diminuir os preconceitos, mito e tabus em procura da convicção da população feminina sobre as vantagens da prevenção contra essa neoplasia (MELO et al, 2012).

\section{CONCLUSÃO}

O enfermeiro possui uma elevada responsabilidade nas ações relacionadas a vacinação e a prevenção precoce do câncer do colo do útero. Porém, infelizmente na maior parte das vezes o enfermeiro limita-se apenas a executar a técnica e não o seu outro papel de educador quanto a promoção da saúde da mulher.

Diante disso, é necessário que o enfermeiro realize ações educativas para aumentar as taxas de vacinação, além de esclarecer notícias falsas, dúvidas frequentes, mostrando as 
informações corretas sobre a vacina e possíveis eventos adversos e construa uma relação com a população na qual é responsável.

Conclui-se que o tema da presente pesquisa é relevante quanto a promoção da saúde da mulher, além de que se pode perceber o papel fundamental que o enfermeiro tem diante do enfrentamento do câncer de do colo do útero, desde da prevenção com a promoção da vacinação contra o HPV.

Foi possível constatar que apesar do enfermeiro ser profissional responsável para ação do controle de câncer de colo do útero e do HPV, ainda encontra inúmeras dificuldades para exercer sua função sendo necessário preparo através de capacitações e conscientizações.

\section{REFERÊNCIAS BIBLIOGRÁFICAS}

AMARAL, M.S.; GONÇALVES, A. G.; SILVEIRA, L. C. G. Prevenção do câncer de colo de útero: a atuação do profissional enfermeiro nas unidades básicas de saúde. Rev Cient Fac Mais, 2017; 197-223. Disponível em: < https://revistacientifica.facmais.com.br/wpcontent/uploads/2017/o4/8-PREVEN\% $\mathrm{C}_{3} \% 87 \% \mathrm{C}_{3} \% 83 \mathrm{O}-\mathrm{DO}-\mathrm{C} \% \mathrm{C}_{3} \% 82 \mathrm{NCER}-\mathrm{DE}-$ COLO-DE-\%C $3 \% 9$ ATERO-A-ATUA\% $\% 3 \% 87 \% \mathrm{C}_{3} \%{ }_{3} \mathrm{O}$-DO-PROFISSIONALENFERMEIRO-NAS-UNIDADES-B\%C3\%8ISICAS-DE-SA\%C3\%9ADE.pdf>. Acesso em: I9 de set. 202I.

BARBOSA, A. M. B. R.; NIQUIRILO, A. T. Eficácia e segurança da vacinação contra o Papiloma Vírus Humano no programa nacional de imunização. Atas de Ciências da Saúde (ISSN 2448-3753), v. 4, n. I, p. o2-II, 2016. Disponível em: <

https://revistaseletronicas.fmu.br/index.php/ACIS/article/view/ro67>. Acesso em: i7 de set. de 202I.

BATISTA, R.C. L. Papel da enfermagem na prevenção, diagnóstico e tratamento do câncer de colo uterino: uma revisão integrativa. Universidade de Brasília-Faculdade de Ceilândia,
Distrito
Federal,
2015 .
Disponível
em:

https://bdm.unb.br/bitstream/10483/10886/r/2015_RenataCristianeLopesBatista.pdf>.

Acesso em: 20 de set. de 2021.

BRASIL. Ministério da Saúde. Secretaria de Vigilância em Saúde. Departamento de Vigilância de Doenças Transmissíveis. Coordenação Geral do Programa Nacional de Imunizações. Guia prático sobre HPV: perguntas e respostas. Brasília: Ministério da Saúde; 2013. Disponível em:< https://portalarquivos2.saude.gov.br/images/pdf/2014/marco/o7/guia-perguntasrepostas-MS-HPV-profissionais-saude2.pdf. > Acesso em: 25 de Set. de 2021. 
BRASIL. Plataforma de capacitação contra o Papilomavírus Humano. Disponível em https://ufpe.unasus.gov.br/moodle_unasus/cursos/hpv_livre. Acessos em: 25 de Set. de 2021.

CABUYA, H. J. B. Estrategias de aceptabilidad de la vacunación contra el virus del papiloma humano: una revisión sistemática. Suma Psicológica, Bogotá, v. 27, n. 2, p. 125-I4I, 2020. Disponível em: < http://www.scielo.org.co/scielo.php?pid=Sor2I$43812020000200125 \&$ script $=$ sci_abstract $\& \operatorname{tn} \operatorname{lng}=$ en $>$. Acesso em: 25 de Set. de 2021.

CAMARGO, T. C.; SOUZA, E. O. Atenção à mulher mastectomizada: discutindo os aspectos ônticos e a dimensão ontológica da atuação da enfermeira no Hospital do Câncer III. Ribeirão Preto, 2003. Disponível em: https://www.scielo.br/j/rlae/a/qsBVM8KmP53WdT4VhsfVvKM/abstract/?lang=pt>. Acesso em: 26 de Set. de 2021.

CARDiAl, M. F. T.; ROTELI-MARTINS, C. M.; NOUD, P.; FRIDMAN, F. Z. Papilomavírus humano (HPV). Femina, p. 94-ıo, 2019. Disponível em: < https://pesquisa.bvsalud.org/ portal/resource/pt/biblio-1046496>. Acesso em: 26 de Set. de 2021.

CARVALHO, A. M. C. Adesão à vacina HPV entre os adolescentes: revisão integrativa. Texto e contexto - Enfermagem, Florianópolis, v. 28, 2019. Disponível em: < https://www.scielo.br/j/tce/a/LxgbWPXJyD8ZCSGwhMbtZRw/?lang=pt>. Acesso em: 27 de Set. de 2021.

COLATINO, P. L. HPV I6 e I8 e o desenvolvimento do câncer do colo uterino. Monografia de pós-graduação em Citologia Clínica - Universidade Paulista e Centro de Consultoria Educacional. Recife - PE, 2010. Disponível em: < https://www.brazilianjournals. com/index.php/BJHR/article/view/7486>. Acesso em: 27 de Set. de 202I.

COSTA, F. K. M.; WEIGERT, S. P.; BURCI, L. Os desafios do Enfermeiro perante a prevenção do câncer de colo do útero. Revista de gestão e saúde, v.17, n. oI, p. 55-62, 2017. Disponível em: https://www.herrero.com.br/files/revista/filefi25a619c4bi8a9gefe6fdf22874fdd6.pdf>. Acesso em: 27 de Set. de 2021.

DA SilvA, L. A. P.; FERREIRA, A. C.; DE OliveirA, M. B. A.; FARIA, T. A. Imunização contra o HPV em escola pública de Paracatu-MG. Saúde \& Transformação Social/Health \& Social Change, v. 7, n. 3, p. 176-181, 2016. Disponível em: < http://stat.necat.incubadora.ufsc.br/index.php/saudeetransformacao/article/view/3900>. Acesso em 27 de Set. de 2021.

DE CARVALHO, K. F.; COSTA, L. M. O.; FRANÇA, R. F. A relação entre HPV e Câncer de Colo de Útero: um panorama a partir da produção bibliográfica da área. 2019. Disponível em: https://portal.unisepe.com.br/unifia/wpcontent/uploads/sites/roool/2019/o2/o21_A-RELA \% ${ }_{3} \% 87 \% \mathrm{C}_{3} \% 83 \mathrm{O}$-ENTRE-HPV-EC\%C3\%82NCER-DE-COLO-DE-\%C3\%9ATERO-UM-PA NORAMA-A-PARTIR-DA- 
PRODU\% $\mathrm{C}_{3} \% 87 \% \mathrm{C}_{3} \% 83 \mathrm{O}-\mathrm{BIBLIOGR} \% \mathrm{C}_{3} \% 8 \mathrm{IFICA}-\mathrm{DA}-\%$ C3\%8IREA.pdf $>$. Acesso em: 28 de Set. de 202i.

DE MELO, M. C. S. C.; VILELA, F.; DE OLIVEIRA SALIMENA, A. M.; DE OLIVEIRA SOUZA, I. E. O enfermeiro na prevenção do câncer do colo do útero: o cotidiano da atenção primária. Revista Brasileira de Cancerologia, v. 58, n. 3, p. 389-398, 2012. Disponível em: $\langle$ https://rbc.inca.gov.br/revista/index.php/revista/article/view/59o.〉 Acesso em: $28 \mathrm{de}$ Set. de 202I.

DENARDiN, J. C. CÂNCER DE COLO DE UTERO E A MÁ ADESÃO DA VACINA CONTRA O PAPILOMA VÍRUS HUMANO (HPV): Uma revisão bibliográfica. DêCiência em Foco, v. 5, n. I, p. 34-51, 2021. Disponível em: < http://revistas.uninorteac.com.br/index.php/DeCienciaemFocoo/article/view/550>.

Acesso em: 28 de Set. de 2021.

INCA. Câncer de colo do útero. 202I. Disponível em: 〈https://www.inca.gov.br/tipos-decancer/cancer-do-colo-do-utero> Acesso em: 07 de jun de 2021.

JORGE, L. L. R.; DA SILVA, S. R. Avaliação da qualidade de vida de portadoras de câncer ginecológico, submetidas à quimioterapia antineoplásica. Revista Latino-Americana de Enfermagem, v. ı8, n. 5, p. 849-855, 2010. Disponível em: https://www.scielo.br/j/rlae/a /ZcJfgtRpMcWgsbcpGVBPdDv/?format=pdf\&lang=pt. Acesso em: 29 de Set. de 202I.

KRABBE, E. C.; PADILHA, A. D. S.; HENN, A.; DAL MOLIN, D. B.; TEIXEIRA, K. J.; JÚNIOR, P. S. D. A.; CARVALHO, T. G. M. L. Vacina contra o HPV e a prevenção do câncer do colo do útero: uma necessidade de avanço na prática cotidiana da ciência da saúde. REVISTA INTERDISCIPLINAR DE ENSINO, PESQUISA E EXTENSÃORevInt, v. 3, n. I, 20I6. Disponível em: 〈https://core.ac.uk/download/pdf/323244774.pdf.> Acesso em: 30 de Set. de 2021.

MACHADO, P. A. T.; DE ALCÂNTARA, A. C. M. Cobertura Vacinal contra o HPV em Meninas de o9 a ir Anos no Município de Rolim de Moura-RO. Revista Enfermagem e Saúde Coletiva-REVESC, v. I, n. 2, p. 74-90, 2017. Disponível em: < https://idonline.emnuvens.com.br/id/article/view/918>. Acesso em: 25 de Set. de 202I.

MEIRELES, L. A.; CUNHA, F. V.; VADOR, R. M. F.; MENÊSES, T. M. F. Atuação do enfermeiro na adesão da imunização do Papilomavírus humano em adolescentes. Brazilian Journal of Health Review, v. 3, n. 6, p. 17413-17427, 2020. <Disponível em: < https://www.brazilianjournals.com/index.php/BJHR/article/view/2086r>. Acesso em: 25 de Set. de 202I.

MISTURA, C.; MISTURA, C.; SILVA, R. C. C. Papel do enfermeiro na prevenção do câncer de colo uterino na estratégia saúde da família. Revista Contexto \& Saúde, v. II, n. 2o, p. II6I-II64, 20II. Disponível em: < https://www.revistas.unijui.edu.br/index.php/ contextoesaude/article/view/1763>. Acesso em: is de Set. de 2021.

MORO, A; SANTOS, C. L.; DE COUTO, M. P.; DE ÁVILA, L. B.; DITTERICH, R. G.; MAZON, L. M. Coberturas vacinais do Papiloma Vírus Humano no contexto brasileiro. Saúde e meio ambiente: revista interdisciplinar, v. 6, n. 2, p. 124-132, 2017. 
Disponível

em: 〈https://www.scielo.br/j/rbepid/a/TStbZmwdZTG3rmZZFsqvNFx/?lang=pt\&format= pdf.> Acesso em: is de Set. de 202I.

NASCIMENTO, R.P. A relação enfermeiro-cliente na consulta preventiva do câncer cérvico-uterino. Universidade Federal de Minas Gerais, Minas Gerais, 2010. Disponível em: $<$ https://ares.unasus.gov.br/acervo/handle/ARES/4560>. Acesso em: 20 de Set. de 2021.

NORA, T. T. D.; PAZ, A. A.; LINCH, G. F. D. C.; PELEGRINI, A. H. W.; WACHTER, M. Z. D. Situação da cobertura vacinal de imunobiológicos no período de 2009-2014. Rev. enferm. UFSM, p. 482-493, 2016. Disponível em: < https://pesquisa.bvsalud.org/portal/ resource/pt/bde-31953>. Acesso em: 22 de Set. de 2021.

PEREIRA, F. B; SOUZA, E. P. Cobertura Vacinal do HPV para Adolescentes: Desafios e Possibilidades. Revista Multidisciplinar e Psicologia, v. II, n. 38, 2017. Disponível em: < https://idonline.emnuvens.com.br/id/article/view/918>. Acesso em: 22 de Set. de 202I.

PICCONI, M. A.; TEYSSIÉ, A. Papilomavirus humanos. In: CARBALLAL, G.; OUBIÑA, J. R. Virologia médica. 4 ed. Ciudad Autónoma de Buenos Aires: Corpus Libros Médicos y Científicos, 2014. Disponível em: < https://portal.unisepe.com.br/unifia/wpcontent/uploads/sites/10ool/2019/o2/o21_A-RELA\%C 3\%87\%C3\%83O-ENTRE-HPV-E-

C\% $\mathrm{C}_{3 \%} \%{ }_{2}$ NCER-DE-COLO-DE-\%C3\%9ATERO-UM-PANORAMA-A-PARTIR-DAPRODU\%C $3 \quad \% 87 \% \mathrm{C}_{3} \% 83 \mathrm{O}-\mathrm{BIBLIOGR} \% \mathrm{C}_{3} \% 8$ IFICA-DA-\%C3\%8IREA.pdf $>$. Acesso em: 20 de Set. de 2021.

SANTOS, M. C. L.; FERNANDES, A. F. C.; CAVAlCANTI, P. P. Consulta ginecológica-motivações e conhecimento da mulher sobre a prevenção do câncer do colo do útero. Rev Rene, v. 5, n. I, 2004. Disponível em: < http://www.periodicos.ufc.br/index.php/rene/article/view/5568>. Acesso em: o8 de Julho de 202I.

SEQUERA, M; MATAMOROS, A; MENDOZA-LEON, M. J. Genotipos de VPH y cambios citológicos cervico-uterino en pacientes de una consulta ginecológica privada del Estado Carabobo, Venezuela. Marzooctubre de 2017. Revista médica Risaralda, Pereira, v. 26, n. I, p. 28- 37, 2020. Disponível em: < http://www.scielo.org.co/scielo.php?pid=Sor2206672020000100028\&script=sci_abstract\&tlng=es $>$. Acesso em: I4 de Set. de 2021.

SILVA, S. A.; DOS ANJOS SOUZA, M. D. S.; DOS SANTOS PORTO, T. N. R.; DE SOUSA SANTOS, E. M.; BALDOINO, L. S.; FEITOSA, G. T.; FERNANDES, C. R. S. Situação vacinal do Papiloma Vírus Humano (HPV) em adolescentes em uma unidade básica de saúde no Maranhão. Revista Eletrônica Acervo Saúde, v. I2, n. Io, p. e4845-e4845, 2020. Disponível em: < https://acervomais.com.br/index.php/saude/article/view/4845>. Acesso em: I4 de Set. de 202I.

SILVA, T. T.; GUIMARÃES, M. L.; BARBOSA, M. I. C.; PINHEIRO, M. F. G.; MAIA, A. F. Identificação de tipos de papilomavírus e de outros fatores de risco para neoplasia intra-epitelial cervical. Revista Brasileira de Ginecologia e Obstetrícia, v. 28, n. 5, p. 285- 29I, 
2006. Disponível em: <https://www.scielo.br/j/rbgo/a/WGw7QRyMD6CN8j LpgtZ893c/?lang=pt.> Acesso em: i6 de Set. de 2021.

VASCONCELOS, C. T. M.; DAMASCENO, M. M. C.; LIMA, F. E. T.; PINHEIRO, A. K. B. Revisão integrativa das intervenções de enfermagem utilizadas para detecção precoce do câncer cérvico-uterino. Revista Latino-Americana de enfermagem, v. 19, n. 2, p. Tela ITela 8, 2orr. Disponível em: 〈https://www.scielo.br/j/rlae/a/sZQBWytDsYwZTs5WHT $\mathrm{FW}_{7} \mathrm{WQ} /$ ?lang=pt $>$. Acesso em: 20 de Set. de 2021.

ZARDO, G. P.; FARAH, F. P.; MENDES, F. G.; FRANCO, C. A. G. D. S.; MOLINA, G. V. M.; MELO, G. N. D.; KUSMA, S. Z. Vacina como agente de imunização contra o HPV. Ciência \& Saúde Coletiva, v. 19, p. 3799-3808, 2014. Disponível em: < https://www.scielo.br/j/csc/a/ vhxgghBGgKKWCL6CXJ69X 7 N/abstract/?lang=pt $>$. Acesso em: 25 de Set. de 202I. 